\title{
Drug dealing on Facebook, Snapchat, and Instagram: A qualitative analysis of novel drug markets in the Nordic countries
}

PhD Jakob Demant ${ }^{a *}$, MSc Silje Anderdal Bakken ${ }^{\mathrm{b}}, \mathrm{PhD}$ Atte Oksanen ${ }^{\mathrm{b}}$, and PhD Helgi Gunnlaugsson ${ }^{\mathrm{d}}$

ACCEPTED IN: Drugs and Alcohol Review

${ }^{a}$ Associate professor, Department of Sociology, University of Copenhagen, Copenhagen, Denmark;

${ }^{b} \mathrm{PhD}$ candidate, Department of Sociology, University of Copenhagen, Copenhagen, Denmark;

${ }^{c}$ Faculty of Social Sciences, University of Tampere, Tampere, Finland;

${ }^{d}$ Department of Sociology, University of Iceland, Reykjavik, Iceland

*Jakob Demant, jd@soc.ku.dk, +45 35321584, Øster Farimags gade 5, 1353

Copenhagen, Denmark

\section{Running head:}

Drug dealing on Social Media

\section{Word count: 4498}

Funding: This was supported by the Scandinavian Research Council for Criminology under grant number 20700034

Conflict of interest: None to declare. 


\begin{abstract}
Aims: Internet use has changed drug dealing over the past decade owing to the emergence of darknet services. Yet, little is known about drug dealing in public online services. This study reports findings from a Nordic comparative study on social media drug dealing. It is the first in-depth study on the increase of digitally mediated drug dealing outside the cryptomarkets.
\end{abstract}

Design and methods: A qualitative study using online ethnography and semi-structured interviews. 107 participants aged 16-45 (mean age 23.1 years), with $83.2 \%$ being male. Data was coded in NVivo using general themes: modus operandi, trust, and risk.

Results: Ethnographical data shows a high degree of drug dealing activity on Facebook, Instagram, Snapchat, and Facebook Messenger. Buyers and sellers also use encrypted platforms, such as darknet forums and the Wickr app on their smartphones. The medium used varies across the countries, as well as motivations for usage in connection with risk perceptions.

Discussion: Despite national differences, social media is a common tool used in selling and buying illegal drugs. Availability affects the prevalence of use of various social media; however, prevalence is also crucial for which media is used. Many of the participants report easily drifting in and out of social media dealing and buying, without being aware of the seriousness of the offence.

Conclusion: Based on the differences in attachment to the seller career, we advise that policing strategies should be supplemented with - and even stand in the back ofprevention campaigns.

Keywords: social media, internet, illegal drugs, drug market, comparative study 


\section{Introduction}

The use of internet-based digital communication tools has developed quickly in the new millennium, especially with the rise of social media, which has changed daily routines globally. Social media is characterised by social networking and easy access to virtually any type of content available $[1,2]$. These two are also combined in the criminal activities taking place online [3-5]

Online drug dealing has been studied intensively since the rise of cryptomarkets on the dark web has made both purchasing and selling drugs possible without the direct threat of being caught. Cryptomarkets facilitate the use of bitcoin and encryption, aiming to ensure that participants' anonymity remains concealed. The most famous example is Silk Road, which was initiated in 2011 but was later shut down by the police [6-8]. Cryptomarket users have been most commonly young males who have decided to buy drugs online for safety reasons [9-12]. Cryptomarkets often build trust systems that enable their functionality even in anonymity $[13,14]$. The illegal sale of drugs is also seen on the clear web [15]Hall, $2016 \# 1074\}$, which is less hidden than cryptomarkets but presents a challenge for law enforcement owing to the vast number of websites on the Internet.

Cell phones are well used in the drug business and were seen as something to watch from the early 2000s [16]. Today's development of smartphones has added internet connectivity, which has resulted in the large development of applications to communicate with others through pictures, text, and sound. Much communication now 
occurs on public social media forums, which are characterised by easy access and low data protection. Earlier studies have shown that illicit online activities also occur using these public routes $[3,17,18]$. Social media is also known for increasingly being the place for establishing initial contact to various forms of offending involving physical meetings, such as prostitution [19]) and arranged fights [20]. How social media is used to deal drugs is, however, unexplored.

Drug-dealing activity on social media has been seen in several public media stories the last few years [22-24]. Social media drug dealing makes the potential availability of drugs to large groups of young people earlier unexposed to drugs. The availability of different types of drugs may tempt users to expand their drug use, as has been seen on the darknet [25]. EMCDDA calls for research providing an understanding of the impact of social media on the demand for drugs [26]. This comparative study of five Nordic countries (Denmark, Finland, Iceland, Norway, and Sweden) meets this call by studying how drug dealing takes place on social media and the modus operandi of sellers and buyers.

\section{Method}

The data collection was based on online ethnography [27, 28] and interviews of online sellers and buyers conducted in Denmark, Finland, Iceland, Norway, and Sweden. Data was collected from September-December 2017 in each country's national language. Eleven local social sciences students and one research assistant collected the data by following the same study protocol, including how to search for data on various social media (e.g., search words), maintaining anonymity, researcher protection tips, dos and don'ts (e.g., lurking and not openly communicating), and an interview guide. 


\section{Online ethnography}

As this field of research was still unexplored, the research process was incited with online ethnography in the national languages. Online ethnography is grounded on the principles of ethnographic research; however, activities take place online [27]. First, we conducted general drug-related searches on various social media, which enhanced our understanding of the openness of drug trading on the platforms. Initial searches were made on Facebook, Instagram, Snapchat, Jodel, and Twitter, from where we decided to focus on Facebook and Instagram, which proved to be the most openly used for drug dealing in three of the countries (Denmark, Iceland, and Sweden). Facebook searches led to information about groups through open drug posts, group invitations in other grey-area groups (e.g., shaming groups and sales groups), and other people's group requests. We then entered groups, which led to other group invitations. On Instagram, drug searches resulted in both open and closed profiles, only hiding images. Data consisted of screenshots of group information, discussions, and posts by sellers, buyers, and admins. All screenshots in this article are lookalike copies only.

\section{Participants}

\section{- $\quad$ Insert Table 1 -}

As shown in Table 1, most of the 107 interviewees were men actively selling drugs, with a mean age of 23. Most interviewees were recruited through the social media on which they operated. In some instances, the team contacted over 100 identified sellers or buyers (from posts or profiles) before getting willing interviewees, which is consistent with other hidden population studies (e.g., [29]. To broaden the recruitment strategy, we posted on 
Reddit and recruited through personal acquaintances (five pax). Reddit posts recruited mostly Norwegian interviewees (approx. 12 pax), as well as 7-10 Swedish and Danish participants, and three Icelanders. The only requirement was having used any type of social media to buy/sell illegal drugs. Interviews were conducted using the encrypted messenger app Wickr on a project smartphone. Most interviewees were familiar with the app and trusted its privacy, preferring it to other interview methods when asked. The anonymity also protected the researchers. Wickr offered the flexibility of time and space, which made it easier for the interviewees, but also required 24/7 researcher availability and left us without any control of the interview context (e.g., at work, drunk, with friends). Interviews lasted between half an hour and two months.

\section{Research process}

As it appeared that a substantial part of social-media-based drug dealing occurs on private one-on-one types of messenger-style social media, in-depth interviews provided the only data source for this aspect. The interviews explored the motivations and risk perceptions that formed participant engagement, or lack thereof.

Large national variations of the modus operandi of tradition were identified, resulting in an unequal amount of data from each country, such as more ethnographic data from countries with more public markets. Our dependence on local assistants trained in the social sciences also affected the scope of data collected in each country.

\section{Data analysis}

First, a content analysis was done in NVivo by interpreting and coding screenshots and interviews based on larger, general codes such as modus operandi, risk, motivation, and 
trust. [30] The codes giving an overview were then recoded into specific codes, such as group information, marketing strategy, emoji, and drug type. The research assistant and a student data collector did all the coding.

\section{Ethics}

The study was approved by the Academic Ethics Committee of Copenhagen University in September 2017. Further, the ethics committees in other Nordic countries were consulted. We informed all interview participants about the study's aims and data management plan (anonymization, translated to English and kept encrypted, only read by project members) and they gave their consent. The anonymity of interviewers and interviewees was maintained using Wickr and by collecting data on specific phones (later cleaned and reset). The datasets were further de-identified and securely saved for analysis.

\section{Results}

Denmark, Sweden, and Iceland have an active public social media market, especially in Facebook groups and on Instagram, while Fins were active in a darknet forum (see Table 2 below). These markets are open for anyone to deal/buy while the use of one-on-one communication apps only is considered private markets, as is seen especially in Norway. This public/private distinction is in-line with traditional drug market literature [16]. Interview data is used for insight into private-market countries while ethnography and interview data provide information on how public markets function.

- Insert Table 2 - 
Despite variations between countries, participants: a) were made aware of the seller through friends or on online groups/profiles before; b) communicated privately on messaging apps where they discussed price and amount; and then c) met physically to exchange cash and drugs.

- $\quad$ Insert Table 3 -

\section{Denmark}

In Denmark, Facebook is one of the most popular places to deal drugs, followed by Snapchat. The drug dealing on Facebook takes place in closed but easily accessible groups ranging from 30 members in new groups to more than 10,000 in political cannabis groups. Eighteen of the 26 Danish groups only concerned drug dealing. Two-thirds of them were related to cannabis only while the others were for cocaine, prescription drugs, MDMA, amphetamine, and mushrooms - often more than one at the same time. The remaining six groups also offered other illegal goods or were interest groups (e.g., growing cannabis). Most group members had male profiles.

The groups were national and sellers had to specify their location and delivery range. Most sellers depended on face-to-face transactions and few offered mail shipment (mostly prescription drugs or cannabis seeds). Meetings were usually arranged through one-onone communication platforms, such as Messenger, Wickr, or by phone. The seller either posted their contact information or informed the buyer they would receive their telephone number/Wickr when sending a private message through Facebook Messenger. Most 
sellers had fake profiles (linked to fake names, fake addresses, and fake personal information) while most buyers had traditional person-related profiles. As the online competition is high, sellers paid high attention to their posts, using various emoji to symbolise drugs (e.g., snow crystal for cocaine) or services (e.g., car for delivery) to attract attention or avoid detection. Carefully planned posts can be seen as a form of professionalism and a reflection of the level of technical and graphical competence of the digital generation, as shown in the screenshot below.

Figure 1. Example of a Facebook seller post

[inset figure 1 here]

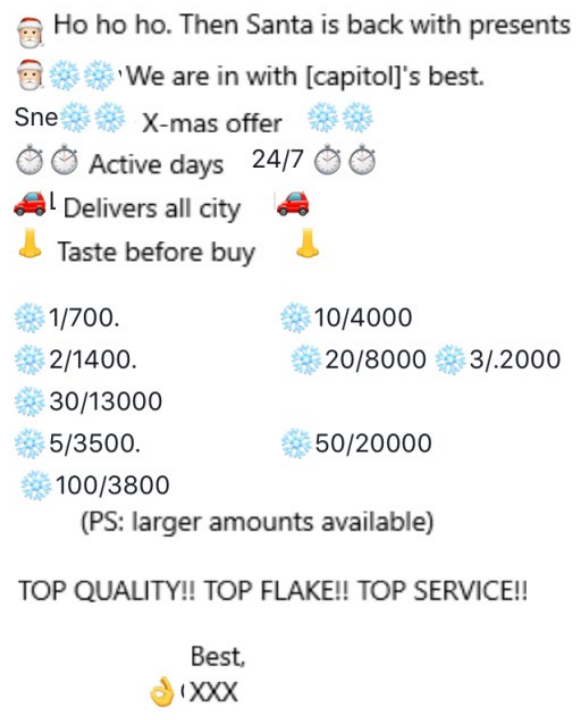

The groups were closed, meaning one must apply for membership to gain access. Access was easily granted and questions were seldom asked by moderators. Some had entry questions to determine “drug-wise” knowledge or one's drug policy views. Some groups were also hidden and, as such, not searchable. To gain access to hidden groups, one would have to know a group member or see people talk about them openly. Further, the same 
sellers and buyers posted across the different open, closed, and hidden groups, which made it possible to quickly be invited to more groups.

Seventy-one per cent of the Danish interviewees only used social media and messenger applications (incl. Wickr) while $29 \%$ also used cryptomarkets, especially to source resale drugs or specific drugs for personal use. Eighty-three per cent used Facebook to buy and/or sell drugs. Other social media used included Messenger, Wickr, Snapchat, WhatsApp, and Jodel. Just below $50 \%$ of the sellers mentioned direct buyer communication through phone calls or SMS. Open social media was often a source to get new contacts, both for sellers and buyers, and it offered easy access to drugs that could be hard to get, as expressed by this Danish buyer/seller:

Interviewer: Why do you think people sell/buy on a social media like Facebook instead of doing it in other ways?

Buyer/seller: I don't know. In my eyes, drugs are something I can get my hands on [from peers] within five minutes, if I want to. So I would say that it's actually easier - especially when it comes to amphetamine and stuff like that. But things like prescription pills, that's not so easy to get hold of. I think that is why [people prefer Facebook].

When contact was established, the planning moved to private one-on-one messages, which was often the preferred way of communicating. All participants had already been using drugs before buying on social media while most sellers had also sold before. The most frequent motivation for using social media to sell/buy drugs was that everyone uses social media for all types of communication; therefore, it feels "natural" and provides a clear opportunity for trading drugs as well.

\section{Sweden}

Sweden also has an active Facebook drug-dealing network. However, it takes place in a more organized way than Denmark, including brand-like names such as Fleamarket 
Stockholm and Fleamarket, and a rating system marking someone 'green' or 'red'. Buyers can choose specific selling groups with only 'green' dealers. The dealing itself follows the same methodology as in Denmark, based on the use of advertising, private messages, and face-to-face exchanges. However, we saw a higher degree of postal shipments, which might be explained by the larger geographical distances in Sweden compared to Denmark. All of the 56 observed groups were drug-related. Most of the groups sold multiple drug types (e.g., cannabis, cocaine, and amphetamine) while a few only sold cannabis and/or prescription drugs. Only a few groups had mixed content (selling weapons).

Sweden's dealing environment seemed more hostile than Denmark's: more weapons on sale, sellers wearing masks and weapons in their profiles, and rough language in posts, often including threats. This might be why some buyers chose to reduce the risks associated with a physical meeting by ordering mail delivery. Sweden was also the only country where interviewees mentioned using the Tor browser or other VPNs to browse Facebook, as well as a high use of cryptomarkets, Wickr, Telegram, and other encrypted communication channels, as this Swedish seller: "The second time [I sold] was on Facebook. I had a VPN and... that's it. I made a fake profile and answered on Wickr.". Again, sellers used fake profiles while buyers were often told to use real profiles to gain trust from sellers, despite the risk. We also observed more female profiles than in the other countries.

Instagram is the second most popular in Sweden. There, sellers have their own closed profiles where they advertise their drug dealing in their profile names or short description. The common Instagram use of posting pictures and marking them with relevant hashtags 
was not done by most sellers and the pictures were most often not of their products but rather some cultural drug or street-style-related pictures of weapons, dogs, posing with friends, etc. The profiles were easily found by searching for drug-related words when situated in Sweden, as is seen in the screenshot below:

Figure 2 of an Instagram seller profile

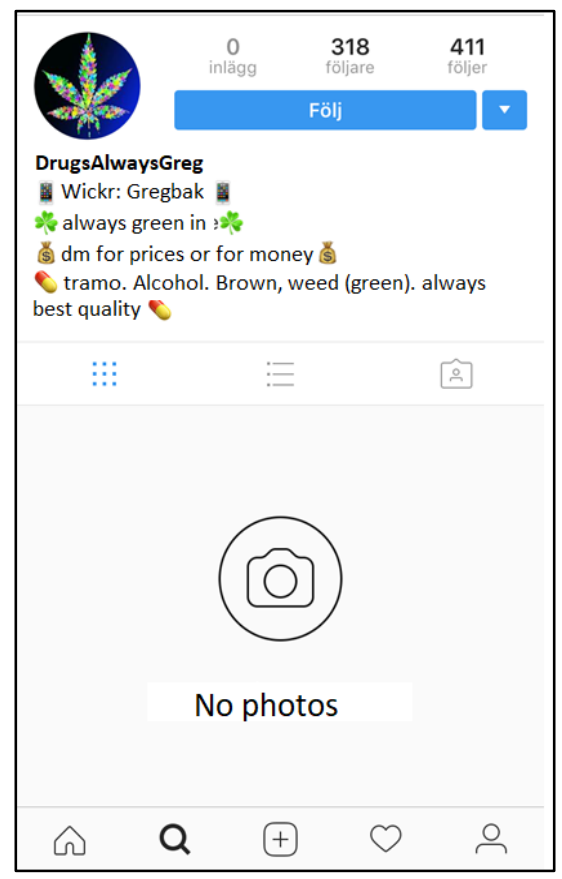

[Inset figure 2 here]

Further contact happened on private messages. Some sellers were more active than others and posted ads as comments in specific groups, such as music groups or political activist groups, thereby attracting attention to their Instagram profiles.

In the interviews, we identified a higher involvement in cryptomarket drug trade than in Denmark. Half of the participants mentioned that they used cryptomarkets and social media for drug trades. The remaining interviewees were all familiar with cryptomarkets but mostly found them unsecure or too complicated. Many sellers resold goods they had bought internationally on the cryptomarkets. All interviewees had used 
Facebook to buy, sell, or both. The interviewees also mentioned using Snapchat, Jodel, Signal, Telegram, Wickr, and Kik. Most learned about social media drug dealing through friends, but it usually took some time before they grabbed the chance, as with this buyer when asked when he heard about dealing via social media:

"Hmm, if we're talking about drugs, then its probably 4-5 years ago. (...) A classmate needed to buy while his dealer was abroad, then another classmate suggested an Instagram page that sold hash. [It passed] 3 years [before I bought]. On Snapchat.”.

Other interviewees were new to drugs after learning about it on social media and their first buy and sale were online. The main reason for using social media was to reach out to a large crowd easily. Sellers' posts also implied that money was a larger motivation among the Swedes than the Danes and Icelandic, and many of the Swedish dealers sold larger quantities (often up to, e.g., 100 grams of cannabis or cocaine) or sold left-overs of private prescription drugs for extra money.

\section{Norway}

In Norway, we found no traces of drug dealing on open social media during our ethnographic fieldwork. In two interviews, we were told about closed Facebook groups for drug dealing; however, we were unable to observe any of these. We identified a few Norwegian profiles on Instagram that were pro drug use (cannabis) but these were not (visibly) linked with dealing. We found one incidence where a person in a post on Jodel offered free MDMA to girls wanting to go on a date with him. Further, a few Snapchat accounts with drug-related names appeared during searches. The only identified public selling was of illicit alcohol, usually sold by exchange students or other foreigners. Insight into the Norwegian market was rather gained through interviews. 
Based on interviews with 35 Norwegian sellers and buyers recruited through snowball sampling and forum advertisements, one-on-one communication media was the preferred way of trading drugs. Sixty-nine per cent used Wickr to buy/sell drugs and $66 \%$ used Snapchat. Only 17\% mentioned using Facebook Messenger and 11\% Instagram. Some interviewees mentioned Yellow, various forums, Telegram, and WhatsApp. Many of the interviewees felt unsafe when using unencrypted social media and they often quickly shifted to Wickr or other channels when discussing drugs, as this seller explains when asked if he thinks hidden Facebook groups are secure: "Absolutely not. It can be read by third parties if it is not encrypted. If someone writes to me on Facebook messenger I give them a warning. If they do it again, I will block them :)". Thirty-four per cent rather used cryptomarkets as the safest option while others did not feel competent enough to use encryption and, therefore, felt it was unsafe in this digital environment.

Using one-on-one communication channels requires inside information to know who to contact. All of the interviewees either bought or sold only to friends or friends of friends. A certain level of trust was already established and it felt safer. Some sellers chose to carry weapons or bring friends when meeting a new buyer. The meeting place was always chosen after careful consideration. Peer-to-peer dealing also led to unclear roles and sellers oftentimes did not perceive themselves as sellers, like this Norwegian buyer:

Buyer: Every now and then I buy for my cousin and various others. (...)

Interviewer: Do you then resell? So that you either get money for it upfront or after the deal?

Buyer: Yes, I need to take a little money on acting as mediator.

This unawareness of the legal severity of their actions was common in all countries.

The Norwegian market was clearly the most network-driven of the five countries, consisting mainly of the social supply of drugs [31, 32]. One-on-one communication was 
not foreign in the remaining four countries; however, they showed a more dynamic relationship between public social media markets and more private social network dealing [33]. Norwegians are exposed to international public social media drug dealing, e.g. sellers from the UK, India, or Sweden, who often showed up in our searches from Norwegian social media profiles. Cryptomarkets are the public markets most used by Norwegians, often combined with other communication apps, which is part of a drift between encrypted and non-encrypted markets. This type of digital drift [34] was especially common in Finland.

\section{Finland}

In Finland, as within the other countries, the research process started with searching for drug dealing on Facebook and Instagram. Instagram searches provided no indication of social media drug-dealing activities. Facebook searches identified social groups for cannabis and psychedelics, where people shared videos and pictures of using drugs. Further, groups for selling cannabis accessories and legal cannabis seeds were identified. However, no open drug ads were found, except for some groups for selling snus tobacco, which is illegal in the EU/EEA, except in Sweden and Norway. The only open communication on drug dealing appeared in two posts where a user asked in English where he could buy cannabis. The user was quickly advised by others that Facebook was not the place for such talk and that he should try darknet markets: "You have to use Torsite Sipulikanava. Google it and you have info. There are always sales! Just check your [location]-page (-)". More than 70\% of the Finnish interviewees used the Finnish cryptomarket forum Sipulikanava, a hidden service on Tor that required a simple registration to access. It functioned much like a Facebook group market: Finnish sellers 
posted ads with their products, price, location, and Wickr information, then the exchange takes place face-to-face.

Hidden communication has been used for many years in the Finnish drug market. Interviewees described the early use of internet relay chats, forums, and encrypted e-mail to discuss drugs, such as this buyer/seller: "In the nineties I used IRC, ICQ and different forums. (...) I still use private IRC, pidgin + otr, telegram, Wickr, Signal and Wire. On some rare occasions I also use Privnote or other disposable online messaging services." These encrypted communication channels were also important for getting into resale and buying for personal use. Presently, most drug trades use a combination of the encrypted forum and Wickr, Telegram, or Signal. Some of the interviewees also mentioned public social media, such as Facebook (53\%), Messenger (40\%), WhatsApp (33\%), Snapchat (47\%), Instagram (13\%), and Tinder (7\%). However, non-encrypted social media platforms were only used with buyers/sellers they already knew or got in touch with through friends. The few that talked openly about drugs usually used code words or fake profiles.

Risk and trust were two important keywords in the Finnish sample. All interviewees saw it as a no-go to discuss drug buying/selling on public social media, both openly and oneon-one. They also told stories about both buyers and sellers being robbed when meeting new contacts, such as this seller's story: 'I've heard about a seller who got his fingers snapped. They had sold some designer drugs to minors near a school, and a kid almost died. Total outsiders found the person and acted, because that kind of shit gives bad name to all of us". Online markets were often preferred because buyers did not need to seek contact with larger criminal groups but rather single, entrepreneurial sellers. Others 
preferred the Sipulikanava forum to postal-shipping cryptomarkets because they could smell, taste, and test the drug before buying it, as delivery was in person. To establish trust between buyer and seller, they usually conversed for a short while before separating after a deal. It is important for the buyers that the sellers are nice. If not, they are reported quite easily with negative comments on the forum. The seller always decided where to meet, and buyers and sellers have various strategies for staying safe, such as carrying weapons (e.g., gas, knife) or bringing a friend.

\section{Iceland}

Facebook is, by far, the most popular form of social media for drug dealing in Iceland. On Facebook, the sellers post quite colourful advertisements and include phone numbers. These posts appear in closed but searchable groups. Most Facebook groups are divided into cities or areas while some include finer grained locality divisions (urban neighbourhood). Interested buyers contact sellers by phone and plan where to meet for the trade. The seller often drives a car, which is where the dealing takes place. This also makes sellers quite movable. The Icelandic groups were larger on average than the other countries'. The 29 groups identified in the fieldwork had between 850 and 2500 group members. Most of the groups were exclusively for trading illegal drugs and specific drug types. Often, sellers posted in multiple groups. One group was in English and a few sellers also posted in English in the Icelandic language groups. This was not seen in the other countries. Similar to Sweden, we observed more female posts than in Denmark.

Compared to the other countries, Icelandic buyers were less active within the groups (seldom posted for sellers to respond). Within the Icelandic seller posts, it was 
common to use pictures or emoji to explain services or products. Sellers used profiles with little information and minimal activity, often consisting of pictures and names of famous movie characters or criminals related to drugs. Wickr or other encrypted applications were rarely used for one-on-one drug sales, as expressed by this buyer when asked if Wickr is used for drug dealing in Iceland: "Not to my knowledge. Not by regular buyers. But probably used by the guys who control the drug market.". They rather preferred using phones or Facebook Messenger as personal communication channels.

All the Icelandic interviewees used Facebook as the only form of social media to buy drugs. Where we have seen a larger social integration between sellers and buyers in the other countries, Icelandic buyers did not mention that they continued to communicate with the seller outside of Facebook. Buyers rather returned to find new sellers when wanting drugs and spent much time hanging around in the groups to do so. Especially, the Swedes and Finns spent time conversing during the meeting: "In face-to-face meeting trust is created by knowing your client and smalltalk (...)" (Finish seller). While the Icelandic quickly exchanged products and money before splitting up: "We decide where to meet, I go there, either I sit in his car or he sits in my car, I hand over the money and he the drugs and that's it." (Icelandic seller and buyer).

Trust in Iceland is built by choosing sellers with correct grammar and no signs of personal drug use rather than spending time communicating with sellers before meeting face-toface. They also presented little knowledge of encryption and cryptomarkets and only one seller knew about encrypted applications for communication (Wickr and Telegram). Rather, cryptomarkets were seen as dangerous and risky and they preferred using social media because it is quick, easy, and felt normal. 


\section{Discussion}

This study provides the first results on social-media-based drug dealing within Nordic countries. Major variation was found across the five nations. In Denmark, Iceland, and Sweden, drug dealing takes place publicly in dedicated closed Facebook groups where sellers announce their goods with pictures, descriptions, and contact information. Instagram was also used in Sweden. In Norway and Finland, we did not observe any public social media drug dealing. However, the interviewees talked about the wide use of Snapchat, Wickr, Messenger, and other one-on-one communication applications, as well as cryptomarkets and darknet forums.

The country differences could reflect both legal and sociocultural differences. Despite having similar societies, Nordic countries differ regarding drug legislation. For example, Denmark has the most liberal drug legislation [38-40]. It seems, however, that legal aspects provide only a partial explanation for the actions taking place. Our data also reflect a variation in social media use for trading. We found that Icelandic traders solely use Facebook, Finnish users prefer Tor network applications, and Norwegians a combination of closed social media and encryption applications.

The prevalence of use of certain social media apps for drug buying depends on knowledge of the applications, as well as the buyer's risk perception. Sellers have a crucial role in deciding what media to use for dealing and buyers follow where the sellers are situated. For example, there were no available public markets on Facebook in Norway and Finland 
and no Wickr use in Iceland. Therefore, social media drug markets are supply driven and that normalisation of drug use, as well as the general frequency of use of certain social media apps, leads to the high availability of illicit drugs on social media.

Our results mark a contrast to previous studies on cryptomarkets underlining the potential harm reduction effects and increased safety $(10,35)$. Although social media drug dealing also relies on sellers advertising on the internet, buyers and sellers placed little focus on the purity of the drugs. On social media, we may see that the availability of MDMA, cocaine, and amphetamines side by side with cannabis may tempt some cannabis users; this requires further research. For example, it would be important to see if the "honeymoon effect" of getting into a wide selection of drugs influences users as it does on cryptomarkets (10).

Most interviewees expressed high unawareness of the severity of their actions, especially when dealing drugs among friends on private social media apps. A combination of the availability of drugs, open communication channels, and requests resulted in potentially drifting in and out of dealing and various drug markets easily. We would, therefore, strongly advise carefulness with traditional policing strategies, as some of this activity may be deflected in different forms of online and/or offline prevention campaigns. The national differences also imply a need for various policies across countries, based on the use of different media and risk perceptions.

\section{Limitations}

Research on online and offline illicit activities meets several challenges. The activity is hidden by its nature and is designed to deflect methods of detection. As such, the 
ethnographic research may not have identified all activities. Following this, the data collectors may also have influenced the amount and types of drug dealing identified. Consequently, the number of groups and activities cannot be used as a precise estimate of the activities but should be used to understand the processes and meanings of it. Steps should be taken to include measures of market types for drug sourcing in general representative surveys to be able to triangulate results.

\section{Conclusion}

Social media is being used to deal drugs, but with great national variances depending on culture and risk perception. The easy access might imply an easy drifting in and out of both dealing and general use, as well as between various drug types, which is especially a risk for young people. We advise using prevention campaigns to educate about the possible risks and consequences of dealing drugs in online settings.

\section{Acknowledgements}

This was supported by the Scandinavian Research Council for Criminology under grant number 20700034.

\section{References}

1. Van Dijck, J., The culture of connectivity: A critical history of social media. 2013: Oxford University Press.

2. Kaplan, A.M. and M. Haenlein, Users of the world, unite! The challenges and opportunities of Social Media. Business Horizons, 2010. 53: p. 59-68.

3. $\quad$ Yar, M., Cybercrime and society. 2013.

4. Wall, D.S., Cybercrime: The transformation of crime in the information age. null. Vol. null. 2007. null.

5. Storrod, M.L. and J.A. Densley, 'Going viral'and 'Going country': the expressive and instrumental activities of street gangs on social media. Journal of youth studies, 2017. 20(6): p. 677-696. 
6. Martin, J., Lost on the Silk Road: Online drug distribution and the 'cryptomarket'. Criminology and Criminal Justice, 2014. 14: p. 351-367.

7. Aldridge, J. and D. Décary-Hétu, Not an 'Ebay for Drugs': The Cryptomarket 'Silk Road' as a Paradigm Shifting Criminal Innovation. Available at SSRN 2436643, 2014.

8. $\quad$ Barratt, M.J., Silk Road: eBay for drugs. Addiction, 2012. 107: p. 683.

9. Barratt, M.J., J.A. Ferris, and A.R. Winstock, Use of Silk Road, the online drug marketplace, in the United Kingdom, Australia and the United States. Addiction, 2014. 109: p. 774-783.

10. Van Hout, M.C. and T. Bingham, 'Surfing the Silk Road': A study of users' experiences. International Journal of Drug Policy, 2013. 24: p. 524-529.

11. Barratt, M.J. and J. Aldridge, Everything you always wanted to know about drug cryptomarkets* (*but were afraid to ask). International Journal of Drug Policy, 2016. 35: p. 1-6.

12. Barratt, M.J., J.A. Ferris, and A.R. Winstock, Safer scoring? Cryptomarkets, social supply and drug market violence. International Journal of Drug Policy, 2016. 35: p. 24-31.

13. Tzanetakis, M., et al., The transparency paradox. Building trust, resolving disputes and optimising logistics on conventional and online drugs markets. International Journal of Drug Policy, 2016. 35: p. 58-68.

14. Bakken, S.A., K. Moeller, and S. Sandberg, Coordination problems in cryptomarkets: Changes in cooperation, competition and valuation. European Journal of Criminology, 2017: p. 1-19.

15. Schifano, F., et al., Psychoactive drug or mystical incense? Overview of the online available information on Spice products. International Journal of Culture and Mental Health, 2009. 2: p. 137-144.

16. May, T. and M. Hough, Drug markets and distribution systems. Addiction Research \& Theory, 2004. 12: p. 549-563.

17. Clough, J., Principles of cybercrime. 2015: Cambridge University Press.

18. Kaakinen, M., et al., Cybercrime Victimization and Subjective Well-Being: An Examination of the Buffering Effect Hypothesis Among Adolescents and Young Adults. Cyberpsychology, Behavior, and Social Networking, 2018. 21(2): p. 129-137.

19. Cunningham, S. and T.D. Kendall, Prostitution 2.0: The changing face of sex work. Journal of Urban Economics, 2011. 69: p. 273-287.

20. Wood, M.A., 'I just wanna see someone get knocked the fuck out': Spectating affray on Facebook fight pages. Crime, Media, Culture, 2018. 14(1): p. 23-40.

21. Forsyth, A.J., Virtually a drug scare: Mephedrone and the impact of the Internet on drug news transmission. International Journal of Drug Policy, 2012. 23(3): p. 198-209.

22. Ward, V. and J. Maidment, Dealers 'using social media sites to sell drugs to teenagers'. The Telegraph, 2017.

23. Horne, M., Drug dealers 'sell openly' on Facebook. The Times, 2018.

24. Ferguson, R.-H., The digital underground: here's how you can buy drugs on social media, right now. Complex Magazine, 2016(June).

25. Barratt, M.J., et al., 'What if you live on top of a bakery and you like cakes?'Drug use and harm trajectories before, during and after the emergence of Silk Road. International Journal of Drug Policy, 2016. 35: p. 50-57.

26. Thanki, D. and B.J. Frederick, eds. Chapter 12: Social Media and Drug Markets. ed. E.M.C.f.D.a.D. Abuse. 2016: Lisbon. 
27. Hine, C., Ethnography and the Internet: Taking Account of Emerging Technological Landscapes. Fudan Journal of the Humanities and Social Sciences, 2017. 10(3): p. 315-329.

28. Hine, C., Ethnography for the internet: Embedded, embodied and everyday. 2015: Bloomsbury Publishing.

29. Dunlap, E. and B.D. Johnson, Gaining access to hidden populations: Strategies for gaining cooperation of drug sellers/dealers and their families in ethnographic research. Drugs \& Society, 1998. 14(1-2): p. 127-149.

30. Altheide, D.L., Reflections: Ethnographic content analysis. Qualitative Sociology, 1987. 10(1): p. 65-77.

31. Coomber, R. and L. Moyle, Beyond drug dealing: Developing and extending the concept of 'social supply' of illicit drugs to 'minimally commercial supply'. Drugs: Education, Prevention and Policy, 2014. 21: p. 157-164.

32. Coomber, R., L. Moyle, and N. South, The normalisation of drug supply: The social supply of drugs as the "other side" of the history of normalisation. Drugs: Education, Prevention and Policy, 2016. 23: p. 255-263.

33. Hough, M. and M. Natarajan, Introduction: Illegal drug markets, research and policy. Crime Prevention Studies, 2000. 11(1-18).

34. Goldsmith, A. and R. Brewer, Digital drift and the criminal interaction order. Theoretical Criminology, 2015. 19: p. 112-130.

35. Munksgaard, R. and J. Demant, Changes in Regional Drug Dealing Networks Implications of Recent Cryptomarket Developments, in Annual Meeting of The American Society of Criminology. 2016, American Society of Criminology: New Orleans.

36. Paquet-Clouston, M.-C., Are Cryptomarkets the Future of Drug Dealing? Assessing the Structure of the Drug Market Hosted on Cryptomarkets. 2016.

37. Rhumorbarbe, D., et al., Buying drugs on a Darknet market: a better deal? Studying the online illicit drug market through the analysis of digital, physical and chemical data. Forensic Science International, 2016. 267: p. 173-182.

38. Moeller, K., Illicit Drug Use Initiation in the Nordic Countries. International Journal of Criminology and Sociology, 2013. 2: p. 79-86.

39. Hakkarainen, P., T. Jetsu, and L. Laursen, The legal framework and the drug control system. NAD Publication, 1996. 31: p. 21-32.

40. Träskman, P.O., Drug control and drug offences in the Nordic countries: A criminal political failure too often interpreted as a success. Journal of Scandinavian Studies in Criminology and Crime Prevention, 2005. 5(2): p. 236256.

41. Aldridge, J., A. Stevens, and M.J. Barratt, Will growth in cryptomarket drug buying increase the harms of illicit drugs? Addiction, 2017. 113(5): p. 789-796.

Tables

Table 1: Participant information

\begin{tabular}{|l|l|l|l|l|}
\hline Country & $N$ & Mean age (SD) & $\begin{array}{l}\text { Male/female } \\
\text { /transgendered }\end{array}$ & $\begin{array}{l}\text { Sellers/buyers } \\
\text { /buyers and sellers }\end{array}$ \\
\hline Denmark & 26 & $23.4(5.6)$ & $22 / 1 /-$ & $10 / 8 / 8$ \\
\hline Finland & 15 & $27.3(7.9)$ & $7 / 5 / 3$ & $3 / 5 / 7$ \\
\hline
\end{tabular}




\begin{tabular}{|l|l|l|l|l|}
\hline Iceland & 7 & $24.8(5.2)$ & $6 / 1 /-$ & $1 / 3 / 3$ \\
\hline Norway & 35 & $21.2(4.3)$ & $34 / 1 /-$ & $8 / 20 / 7$ \\
\hline Sweden & 24 & $22.9(5.2)$ & $24 /-/-$ & $13 / 3 / 8$ \\
\hline Total & $\mathbf{1 0 7}$ & $\mathbf{2 3 . 1 ( 5 . 6 )}$ & $\mathbf{8 9 . 4 \% / 7 . 7 \% / 2 . 9 \%}$ & $\begin{array}{l}\mathbf{3 2 . 7 \%} / \mathbf{3 6 . 5 \%} / \\
\mathbf{3 0 . 8 \%}\end{array}$ \\
\hline
\end{tabular}

Table 2: Prevalence of digital drug markets in Nordic countries

\begin{tabular}{|c|c|c|}
\hline Country & $\begin{array}{c}\text { Public digital market } \\
\text { (Facebook, Instagram, forums) }\end{array}$ & $\begin{array}{c}\text { Semi-public/private digital market } \\
\text { (Snapchat, Wickr, messaging applications) }\end{array}$ \\
\hline Denmark & High & Medium \\
\hline Sweden & High & Medium \\
\hline Norway & Low & High \\
\hline Finland & High & Medium \\
\hline Iceland & High & Low \\
\hline
\end{tabular}

Table 3: Key information on most popular social media and drugs and the number of interviews and Facebook groups by country

\begin{tabular}{|c|c|c|c|c|}
\hline Country & Social media & $\begin{array}{c}\text { Number } \\
\text { of } \\
\text { interviews }\end{array}$ & $\begin{array}{l}\text { Number of } \\
\text { Facebook } \\
\text { groups }\end{array}$ & $\begin{array}{c}\text { Top three drugs } \\
\text { (from Facebook } \\
\text { posts) }\end{array}$ \\
\hline Denmark & $\begin{array}{c}\text { Facebook, Messenger, } \\
\text { Wickr }\end{array}$ & 26 & 26 & $\begin{array}{c}\text { Cannabis, } \\
\text { cocaine, } \\
\text { prescription drugs }\end{array}$ \\
\hline Finland & $\begin{array}{l}\text { Darknet, Wickr, other } \\
\text { encrypted apps }\end{array}$ & 15 & - & - \\
\hline Iceland & Facebook & 7 & 30 & $\begin{array}{c}\text { Cannabis, } \\
\text { prescription } \\
\text { drugs, } \\
\text { ecstasy/MDMA }\end{array}$ \\
\hline Norway & $\begin{array}{c}\text { Wickr, Snapchat, } \\
\text { darknet }\end{array}$ & 35 & - & - \\
\hline Sweden & $\begin{array}{c}\text { Facebook, Wickr, } \\
\text { darknet }\end{array}$ & 24 & 57 & $\begin{array}{l}\text { Cannabis, } \\
\text { prescription } \\
\text { drugs, } \\
\text { amphetamine }\end{array}$ \\
\hline
\end{tabular}

